\title{
Highlights and Perspectives on Evolutionary Neuroscience
}

\section{Brain, Behavior and Evolution}

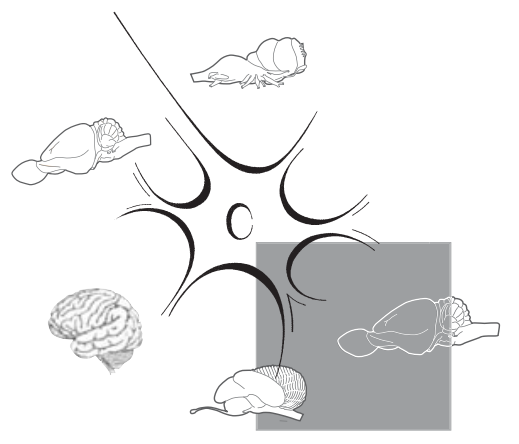

The International Congress of Neuroethology, which took place August 2-7, 2010 , in the Spanish city of Salamanca, is a meeting that I always look forward to attending. One reason I enjoy it is that I feel at home there. Attendees have an appreciation for comparative approaches and the role that evolution played in shaping nervous systems. In thinking about who attends the neuroethology congress and why, I started ruminating about the nature of neuroethology, its roots, its stem, and its branches.

As noted by many authors, neuroethology draws from a wide variety of intellectual fields [see reviews by Bullock, 1981; Hoyle, 1984; Pfluger and Menzel, 1999]. One of those fields is ethology, which was once characterized by Niko Tinbergen as simply 'the biological study of behavior' [Tinbergen, 1963]. Tinbergen and his fellow recipients of the 1973 Nobel Prize in Physiology or Medicine, Konrad Lorenz and Karl von Frisch, had the great insight that behavioral characteristics, just like structural and physiological characteristics, can be studied mechanistically. In an essay written on the occasion of Lorenz's 60th birthday, Tinbergen discussed how a mechanistic understanding of behavior was proceeding from several directions and predicted that the ethological perspective would merge with those of neurophysiology, physiological psychology, and molecular biology. He suggested 'physiology of behavior' as a general name for the nascent field. But he also realized that it is

\section{The Nature of Neuroethology}

\author{
Paul S. Katz \\ Neuroscience Institute, Georgia State University, Atlanta, Ga., USA
}

important to recognize other aspects of behavior besides causation: survival value, evolution, and development [Tinbergen, 1963].

The merger of these approaches for understanding behavior soon arrived as the techniques developed. The term 'neuroethology' entered the literature at about the same time that Tinbergen wrote his essay. The first instance that I know of is a study that uses brain stimulation to alter the mood or motivation of cats [Brown and Hunsperger, 1963]. The term increased in popularity in the 1970s. By 1976, the Society for Neuroscience started including 'neuroethology' as a session topic. A NATO Advanced Sciences Institute on 'Advances in Vertebrate Neuroethology' in 1981 [Ewert et al., 1981] provided the impetus for the founding of the International Society for Neuroethology (http://neuroethology.org). The first International Congress of Neuroethology was then held in Tokyo in 1986 and has been held every 3 years since then. Due in part to their popularity, the congresses will now be held every 2 years, starting 2012 at the University of Maryland in College Park, Md., USA.

One of the characteristics of a neuroethology congress that makes it intellectually stimulating is the shear number of different phyla represented as research subjects. Among the 10 plenary lectures, 18 symposia, and 400 poster presentations, one could find research on rats, mice, nonhuman primates, and humans. But there was also work on other mammals includ- ing bats, harbor seals, possums, and naked mole rats. Indeed, there was a plethora of work on other vertebrate taxa. Among fish, I found abstracts on electric fish, blind cave fish, cichlid fish, zebrafish, flatfish, trout, mosquitofish, piauçu fish, lamprey, brown-banded bamboo shark, and the sex-changing rock hind. Various reptiles and amphibians were well represented. Research on birds included the favorites: owls and zebra finch, but also sparrows, quails, parakeets, pigeons, and wrens.

There were a substantial number of presentations on invertebrates, in particular insects. In addition to the standard genetic model, Drosophila, other insects represented included: moths, bees, ants, dragonflies, stick insects, blow flies, dung beetles, cockroaches, locusts, and butterflies. Other arthropods included spiders and crustaceans. Finally, there was a respectable showing of research on molluscs (cephalopods, sea slugs, and snails), annelids (leech), and another favorite genetic model, the nematode Caenorhabditis elegans.

One might be excused for thinking that the neuroethology congress is simply a gathering of research on the neural basis of behavior in weird animals. Several reasons have been put forward for this broad comparative approach. One is Krogh's principle, which states: 'For a large number of problems there will be some animal of choice or a few such animals on which it can be most conveniently studied' [Krogh,

\section{KARGER}

Fax +4161306 1234 E-Mail karger@karger.ch www.karger.com (c) 2010 S. Karger AG, Basel

0006-8977/10/0764-0163\$26.00/0

Accessible online at: www.karger.com/bbe
Paul S. Katz

Neuroscience Institute, Georgia State University

PO Box 5030

Atlanta, GA 30302-5030 (USA)

Tel. +1 404413 5398, Fax +1 404413 5446, E-Mail pkatz@gsu.edu 
1929]. For example, John Simmers presented a plenary lecture about work in his lab using the tadpole of the African clawed frog, Xenopus laevis, to study gaze stabilization. The accessibility of this system has allowed the researchers to discover an efference copy of the spinal locomotor signal that moves the eyes in such a way as to compensate for body movements during swimming. Although these results are likely to have implications for understanding the control of eye movements in mammals, it is unlikely that such a clean demonstration could have been obtained using a mammalian preparation.

A more famous example of Krogh's principle is the barn owl's auditory system, which has been used as a general model for auditory localization because the behavior, anatomy, and physiology of this species make it convenient to study [Konishi, $2000,2003]$. In this way, the barn owl is considered a champion auditory system. However, Krogh's principle relies in part on the assumption that homologous structures operate in an analogous fashion. There is evidence to suggest that tympanic ears evolved independently a number of times [Schnupp and Carr, 2009]. In her Heiligenberg Lecture, Catherine Carr elegantly compared research on sound localization in the barn owl to sound localization in rodents, which rely more on inhibition than on delay lines. She questioned whether this was a phylogenetic difference or a size difference. Work on chickens, which have smaller heads than owls, suggests that phylogenetic constraints are more important than adaptation to a particular head size in determining the type of computation that is used for sound localization. Thus, a comparative approach is needed to determine if the solution used by a species is phylogenetically constrained to some animals, but not others, or is a general solution to a universal problem, such as sound localization.

It is worth noting that in addition to his oft-repeated principle, Krogh made the following statement, which is not as wellknown: 'I want to say a word for the study of comparative physiology also for its own sake. You will find in the lower animals mechanisms and adaptations of exquisite beauty and the most surprising character, and I think nothing can be more fascinating than the senses and instincts of insects as revealed by the modern investigations' [Krogh, 1929]. I think that much of the work at the neuroethology congress results from a rejoicing in the splendid palette of nature. I was fascinated to learn from work by Mark Alkema that the nematode C. elegans has an escape response to specialized loops formed by fungi. Nematodes lacking touch sensitivity were caught in these tightening nooses. I could list many other talks and posters that were just as fascinating for the novelty that nature produces.

As predicted by Tinbergen, different fields are converging in our understanding of behavior. There were several presentations by people, who would not consider themselves 'neuroethologists', but whose work is of value in understanding the neural basis of natural behavior. One of the highlights of the meeting for me was a talk by Maureen Neitz entitled 'Curing color blindness in an adult primate using gene therapy' [see Mancuso et al., 2009]. Although this has important clinical implications, it is also relevant to people studying the development and evolution of visual behavior. In the other direction,
Daniel Margoliash's work on the role of sleep in consolidation of memory in song birds has important clinical implications that derive from classic neuroethological research [Margoliash, 2005].

The technological advances that have been made since the first neuroethology congress are nothing short of astounding. The use of modern neurogenetics and genomics has revolutionized our molecular understanding of behavior. Hans Hofmann gave an outstanding plenary talk about integrating genomic, hormonal, and behavioral approaches for exploring the social behavior of cichlid fishes. The use of fMRI in humans (and even in birds), has now allowed direct comparison of the neural processes involved in speech and vocalizations in humans and other animals. Advances in telemetric recording provide researchers with the ability to record neural activity in freely behaving animals including birds and even dragonflies. These advances are allowing researchers to probe the complexities of behavior under natural conditions.

The nature of neuroethology, like nature itself, is to continue to evolve and adapt to the latest questions using the latest techniques. As fields of interest merge and barriers break down, real progress can be made in understanding the neural basis of behavior. I am very enthused and excited about this field and look forward to the next congress.

\section{Acknowledgements}

The author's work is funded by grants from NSF and support from the Brains \& Behavior program at Georgia State University.

\section{References}

Brown JL, Hunsperger RW (1963): Neuroethology and the motivation of agonistic behaviour. Animal Behav 11:439-448.

Bullock TH (1981): Implications for neuroethology from comparative neurophysiology; in Ewert JP, Capranica RR, Ingle DJ (eds): Advances in Vertebrate Neuroethology. New York, Plenum Press, pp 53-75.

Ewert JP, Capranica RR, Ingle DJ (1981): Advances in Vertebrate Neuroethology. New York, Plenum Press.

Hoyle G (1984): The scope of neuroethology. Behav Brain Sci 7:367-381.
Konishi M (2000): Study of sound localization by owls and its relevance to humans. Comp Biochem Physiol A Mol Integr Physiol 126:459469.

Konishi M (2003): Coding of auditory space. Annu Rev Neurosci 26:31-55.

Krogh A (1929): The progress of physiology. Amer J Physiol 90:243-251.

Mancuso K, Hauswirth WW, Li Q, Connor TB, Kuchenbecker JA, Mauck MC, Neitz J, Neitz M (2009): Gene therapy for red-green colour blindness in adult primates. Nature 461:784787.
Margoliash D (2005): Song learning and sleep. Nat Neurosci 8:546-548.

Pflüger HJ, Menzel R (1999): Neuroethology, its roots and future. J Comp Physiol A 185:389392.

Schnupp JW, Carr CE (2009): On hearing with more than one ear: lessons from evolution. Nat Neurosci 12:692-697.

Tinbergen N (1963): On aims and methods of ethology. Zeitschrift für Tierpsychologie 20: 410-433. 